\title{
Conditional deletion of platelet derived growth factor receptor alpha (Pdgfra) in urorectal mesenchyme causes mesenchyme apoptosis and urorectal developmental anomalies in mice
}

\author{
Chen Qian ${ }^{1,2} \cdot{\text { Zhongluan } \mathrm{Wu}^{1} \cdot \text { Roy Chun-Laam Ng }}^{1,3} \cdot$ Maria-Mercè Garcia-Barceló $^{1,4} \cdot$ Zheng-Wei Yuan $^{5} \cdot$ \\ Kenneth Kak Yuen Wong ${ }^{1}$ • Paul Kwong Hang Tam ${ }^{1,4}$ • Vincent Chi Hang Lui ${ }^{1,4}$
}

Received: 17 April 2018 / Revised: 1 August 2018 / Accepted: 7 August 2018 / Published online: 15 October 2018

(c) ADMC Associazione Differenziamento e Morte Cellulare 2018

\begin{abstract}
In mammals, urorectal development starts at early embryonic stage, defective urorectal development results in anorectal malformations, which are common congenital developmental defects of the anus and the urethra in newborns. The etiology and embryology of the defects are still largely unknown. Platelet-derived growth factor receptor alpha (Pdgfra) is a cell surface receptor tyrosine kinase, upon binding to its ligands (Pdgfa-d), mediates intracellular signaling and regulates embryonic development. The expression of Pdgfra is tightly regulated in the developing urorectal mesenchyme, and its dysregulation is associated with urorectal defects in animals with urorectal defects. Knockout of Pdgfra induces early embryo lethality which precludes investigation of $P d g f r a$ in urorectal development. To address the temporal requirement of Pdgfra in urorectal development, we conditionally deleted Pdgfra in Pdgfra-expressing tissues using a tamoxifen inducible Cre-loxP approach in mice, examined the urorectal development in Pdgfra conditional knockout (Pdgfra-cKO) embryos. We showed that conditional deletion of Pdgfra in Pdgfra-expressing tissues at E10-E11 caused cloaca septation defect, anteriorly displaced anus, defective urogenital folds development and abnormal urethra tubularization in both male and female mice. Furthermore, we showed that $P d g f r a$ was required for the survival of urorectal mesenchyme, deletion of $P d g f r a$ caused apoptosis in the peri-cloacal, the peri-urethra and the urorectal septum mesenchyme of Pdgfra-cKO mutants, associated with an induction of p53, Ndrg1 and activation of caspase-3 in Pdgfra-cKO embryos. In conclusion, Pdgfra is required for the development and survival of the urorectal mesenchyme in embryo, dysregulated Pdgfra signaling induced urorectal defects in mice resembling human congenital diseases of anorectal malformations and hypospadias. Perturbation of PDGFRA signaling may contribute to anorectal malformations and hypospadias in human.
\end{abstract}

This author contributed equally: Chen Qian.

Edited by M. Piacentini

Electronic supplementary material The online version of this article (https://doi.org/10.1038/s41418-018-0216-2) contains supplementary material, which is available to authorized users.

Vincent Chi Hang Lui

vchlui@hku.hk

1 Department of Surgery, LKS Faculty of Medicine, The University of Hong Kong, Hong Kong, SAR, China

2 Department of Obstetrics and Gynecology, Renji Hospital Affiliated to Shanghai Jiaotong University School of Medicine, Shanghai, China

\section{Introduction}

The external genitalia development could be divided into three phases: genital tubercle (GT) outgrowth, cloaca septation and urethra tubularization. GT outgrowth is initiated by peri-cloaca mesenchymal proliferation resulting in a paired genital swelling on either side of the cloaca (an endoderm-lined cavity at the caudal end of mammalian embryos), that fuse medially accompanied by the formation

3 Department of Medicine, LKS Faculty of Medicine, The University of Hong Kong, Hong Kong, SAR, China

4 Dr Li Dak-Sum Research Centre, The University of Hong KongKarolinska Institutet Collaboration in Regenerative Medicine, Hong Kong, China

5 Key Laboratory of Health Ministry for Congenital Malformation, Shengjing Hospital, China Medical University, Shengyang, China 
of the urethral plate epithelium (the future urethra epithelium) at the ventral midline of the GT to form the future external genitalia [1]. During cloaca septation, the urorectal septum (urs), an endoderm-lined mesenchyme, proliferates and elongates from the ventral body wall to the cloaca membrane $(\mathrm{cm})$. The proximal $\mathrm{cm}$ starts to regress when the apical urs endoderm approaches the $\mathrm{cm}$ leading to the urethral duct and the anal opening formation, marking the completion of cloaca septation. The external genitalia development prior to the urethra tubularization is androgenindependent and is morphologically indistinguishable between male and female embryos [2]. In contrast, the urethra tubularization phase is androgen-dependent and hence different between males and females in humans and many other animal species.

In male, the external genitalia develop into the penis with the urethral tube running along its whole length. Whereas in female, the external genitalia develop into the clitoris, the urethra is shorter and emerges above the vaginal opening. Incomplete urethra tubularization results in hypospadias in male, which involves an abnormally placed urethra orifice at the ventral side of the penis. The corresponding defect in females is an opening of the urethra into the vagina. Hypospadias are among the most common birth defects of the male genitalia, and the worldwide incidence ranges from 5 to 34 per 10,000 live births [3]. In most cases, the cause of this birth defect is still obscure. Hence, a better understanding of the developmental mechanisms of genital tubercle will provide insights on the pathogenesis of hypospadias.

Platelet-derived growth factor (PDGF) was characterized as a serum protein that stimulated the growth and migration of vascular smooth muscle cells, fibroblasts and glial cells $[4,5,6]$. In human and mouse, the PDGF family is composed of four different polypeptide chains (PDGF-A, B, C, and D) encoded by four different genes (PDGF-A, B, C, and D) [7, 8, 9]. PDGFs are secreted as homodimeric proteins (PDGF-AA, BB, CC, and DD), and only PDGF-A and PDGF-B are able to form heterodimer of PDGF-AB [9]. The PDGF signaling network consists of four ligands, PDGFAD, and two cell surface receptors, PDGFRA and PDGFRB [10, 11]. PDGF-PDGFR signaling controls cellular proliferation, survival, migration and differentiation [12, 13].

PDGFRA is a transmembrane receptor tyrosine kinase with an extracellular ligand binding domain and an intracellular tyrosine kinase domain, and binds homodimers of PDGF-A, PDGF-B, PDGF-C and heterodimer PDGF-AB $[10,11]$. PDGF binding dimerizes PDGFRAs and activates the kinase activity, which in turn auto-phosphorylate intracellular tyrosine residues. There are a total of 8 tyrosine residues in the intracellular domain of PDGFRA and the signaling molecules that interact with these tyrosine residues have also been identified [14]. Functions of these downstream signaling molecules in the mediation of
PDGFRA signaling are tissue context dependent, and PI3Kmediated PDGFRA signaling is the major intracellular cascade in the regulation of survival and proliferation in skeletal development via p53 [15].

In mouse, Pdgfra was broadly expressed in the primitive endoderm and mesoderm derivatives thorough embryogenesis, Pdgfra mRNA was detected in the visceral endoderm at E6.5, later after gastrulation, Pdgfra mRNA was detected in many mesenchyme derivatives, including the somites, limb bud and branchial arches [16, 17, 18]. Deletion of Pdgfra induced embryonic lethality at around E11, and multiple development defects in Pdgfra null embryos [12, 13, 19]. However, early death of Pdgfra null embryos precluded the functional investigation of Pdgfra in urorectal development [13]. Abnormal PDGF signaling has recently been shown to associate with defective external genitalia development in human [20].

To address the temporal requirement of Pdgfra in urorectal development, we conditionally deleted Pdgfra in $P d g f r a$-expressing tissues at different embryonic stages using a tamoxifen inducible Cre-loxP approach in mice, examined the urorectal development in Pdgfra conditional knockout embryos. We showed that conditional deletion of Pdgfra in Pdgfra-expressing tissues at E10-E11 caused cloaca septation defect, abnormal urethra tubularization in mice. Furthermore, our data also showed that Pdgfra was required for the survival of urorectal mesenchyme in normal development, deletion of Pdgfra caused cell death of the urorectal mesenchyme.

\section{Methods and materials}

\section{Generation of ethylenethiourea induced rat models of anorectal malformations}

Ethylenethiourea (ETU) solution was prepared by dissolving ETU powder in water to give a final concentration of $1 \%(\mathrm{~W} / \mathrm{V})$, and stored at $4{ }^{\circ} \mathrm{C}$. Outbred Wister rats $(250-300 \mathrm{~g})$ of 10 to 12 weeks of age were mated, and appearance of vaginal plug in the female rat the morning after mating was timed as the gestational day 1. The pregnant rats were given a single dose of ETU at gestational day 11 by gavage feeding $(12.5 \mathrm{ml} / \mathrm{kg}$ body weigh). ETU treated and un-treated litters were collected at E14.5. Urorectal regions of treated embryos $(n=9)$ with ARM phenotypes and un-treated control embryos $(n=8)$ were dissected for RNA isolation and processed for Microarray analysis using GeneChip ${ }^{\circledR}$ expression arrays Rat Expression Set 230 or for real-time PCR validation. Labelling, hybridization and signal detection were performed following standard protocols. Genes identified to be up or down-regulated in ETU treated ARM embryos were 
confirmed by real-time PCR analysis on a separate biological replicates.

\section{Mice and genotyping}

The Pdgfra ${ }^{f l f l}$ [13] and Pdgfra ${ }^{C r e / E R T}$ (B6N;SJL-Tg(Pdgfr-acre/ERT)467Dbe/J) [21] mouse strains were purchased from The Jackson Laboratory. The $P d g f r a^{f l f l}$ mice were maintained in C57BL/6JEi, the Pdgfra ${ }^{C r / E R T}$ mice were maintained in $C 57 B L / 6 N J$. All mice were supplied with food and water ad libitum, and kept under pathogen-free condition with a $12 \mathrm{~h}$ light/dark cycle. The morning the vaginal plug was observed was considered as embryonic day 0 (E0). All the animal experiment protocols were approved by the Committee on the Use of Live Animals in Teaching \& Research, The University of Hong Kong (CULATR No.: 3123-13, 3368-14; 3566-15).

\section{Genotyping}

Genomic DNA was extracted from $2 \mathrm{~mm}$ tail clip using PBND extraction method. PCR genotyping of mice and copy number assay to distinguish Pdgfra ${ }^{\text {Cre/ERT }}$; Pdgfra ${ }^{f / f l}$ $(P d g f r a-c K O)$ and Pdgfra ${ }^{C r e / E R T} ; P d g f r a a^{f l+}$ were performed as described [22].

\section{Tamoxifen induction}

Tamoxifen stock $(20 \mathrm{mg} / \mathrm{ml}$ of corn oil) was prepared by warming tamoxifen (Sigma) in corn oil and $0.1 \mathrm{mg}$ per gram of body weight was administered by intragastric gavage to pregnant mice.

\section{Histology examinations}

Embryos were fixed in PFA/PBS (4\% (w/v) paraformaldehyde (Sigma-Aldrich, Steinheim, Germany) in PBS (phosphate-buffered saline, $\mathrm{pH}$ 7.2; Sigma-Aldrich, Steinheim, Germany)) for $36 \mathrm{~h}$ at $4{ }^{\circ} \mathrm{C}$, dehydrated in graded series of alcohol (Merck, Darmstadt, Germany), cleared in xylene (RCI Labscan Ltd, Bangkok, Thailand) before being embedded in paraffin (Leica Biosystems, Richmond, IL USA). Sections ( $8 \mu \mathrm{m}$ in thickness) were prepared, mounted onto TESPA-coated microscope glass, and stained with hematoxylin and eosin following standard protocol. Photos were taken with the Olympus SZX7 microscope mounted with the Olympus DP71 High Resolution Color Digital Camera.

\section{TUNEL assay}

Apoptotic cells on sections were detected using In Situ Cell Death Detection Kit following manufacturer's protocol
(Roche Applied Science, Indianapolis, IN, USA). Images were taken with Nikon Eclipse 80i microscope (Melville, NY, USA) mounted with SPOT RT3 microscope digital camera (DIAGNOSTIC Instruments, Inc., Sterling Heights, MI, USA) under fluorescence illumination for the DAPI + ve nuclei and TUNEL + ve cells. Photos were compiled using Adobe Photoshop 7.

To quantitate the apoptosis of the mesenchyme surrounding the urethra and cloaca, photos of the TUNEL stained coronal sections of the urorectum of the control and Pdgfra-cKO embryos were taken, total number of cells of the peri-urethra and peri-cloaca mesenchyme were quantitated by counting DAPI + ve nuclei and apoptotic cells were quantitated by counting TUNEL + ve nuclei. Percentages of apoptotic cells of the respective regions of Pdgfra$c K O$ and control embryos were calculated by (TUNEL + ve nuclei/DAPI + ve nuclei) $x 100 \%$. Eight embryos of each group were included for the analysis, six sections of each embryos of the urethra and cloaca region were examined for the quantitation of the apoptosis. Percentages of apoptosis were shown as mean \pm S.D.

\section{Statistical analysis}

Student's t Test was performed to calculate the differences between groups, and $p$ value less than 0.05 was regarded as statistically significant.

\section{Western blotting}

Urorectal tissues $(0.5 \mathrm{~g})$ of Pdgfra-cKO and control littermates were harvested and homogenized with $1 \mathrm{ml}$ Lysis Buffer on ice for $30 \mathrm{~s}$ (For $1 \mathrm{ml}$ Lysis Buffer, $100 \mu \mathrm{l}$ 10xLysis Buffer (Bio-Rad), $10 \mu \mathrm{l}$ of PI (Protease Inhibitor, Bio-Rad) and $1 \mu \mathrm{l}$ of PMSF (0.1 M in isopropanol, BioRad) were added). After homogenization, the lysates were centrifuged at $14,000 \mathrm{rpm}$ for $30 \mathrm{~min}$ at $4{ }^{\circ} \mathrm{C}$, and the supernatant was transferred to new tubes and stored at $-80{ }^{\circ} \mathrm{C}$.

Pooled extracted protein $(20 \mu \mathrm{g})$ of 6 urorectum was resolved by electrophoresis on a standard $8 \%$ denaturing polyacrylamide gel, and then electro-transferred onto PVDF membranes using mini Trans-blot cell (Bio-Rad, Hercules, CA, USA). After transfer, the PVDF membrane was rinsed by TBS-T ( $\mathrm{pH} 7.6$ ), and then blocked with $5 \%$ non-fat milk in TBS-T for $2 \mathrm{~h}$. After washing with TBS-T for $5 \mathrm{~min}$ twice, the membrane was incubated with corresponding primary antibody (Supplementary Table 1) at $4{ }^{\circ} \mathrm{C}$ overnight by gentle shaking. Followed by washing with TBS-T for $15 \mathrm{~min}$ thrice, the membrane was incubated in HRPconjugated secondary antibody for $2 \mathrm{~h}$ by gentle shaking. The membrane was rinsed with TBS-T for 15 min thrice with gentle shaking to remove the unbound secondary 
antibody. Signals were visualized by ECL assay (GE Healthcare Amersham ECL and Western Blotting Detection System) following manufacturer's protocol, and detected by SYNGENE GBox-F3-E. The molecular weight of the positive band was determined by comparing their molecular weight with proper protein ladder (Fermentas, Gern Burnie, MD, USA) on the membranes.

\section{RT-PCR analysis and real-time PCR (qPCR) analysis}

RNA was extracted from E12.5 urorectum using RNeasy ${ }^{\circledR}$ Mid Kit (Qiagen) according to the manufacturer's protocol. The extracted RNA was treated with gDNA Eraser to remove genomic DNA. Complementary DNA was synthesized using (PrimeScript ${ }^{\mathrm{TM}}$ RT reagent Kit with gDNA Eraser, Perfect Real Time, Cat. \#RR047Q) following the manufacturer's protocol.

PCR was performed in $25 \mu \mathrm{l}$ of reaction mixture containing PCR buffer (Roche); $\mathrm{MgCl}_{2}$ (2.5 mM); dNTP $(0.2 \mathrm{mM}$ each); forward and reverse primers $(0.1 \mathrm{nmole}$ each); $3 \mu$ DNA template and 2.5 units DNA polymerase (QIAGEN; HotStart Taq), with 1\% Betanine. Amplification was performed with forward and reverse primers specific for Pdgfra and 18s RNA. Primers: Pdgfra-forward, 5'-GGACTTACCCTGGAGAAGTGAGAA-3'; Pdgfrareverse: 5'-ACACCAGTTTGATGGATGGGA-3'; betaactin-forward: 5'-ACCCGCGAGCACAGCTTCTTT-3'; beta-actin-reverse: $\quad 5^{\prime}$-GGAGCCGTTGTCGACGACCA $-3^{\prime}$. The initial denaturation was performed at $95^{\circ} \mathrm{C}$ for 5 min, PCR reaction was performed with appropriate cycle numbers described as follows: $30 \mathrm{~s}$ denaturation at $95^{\circ} \mathrm{C}$, $60 \mathrm{~s}$ annealing at specific temperature, $60 \mathrm{~s}$ extension at $72{ }^{\circ} \mathrm{C}$ for each cycle. An additional extension step was carried out for $10 \mathrm{~min}$ at $72{ }^{\circ} \mathrm{C}$. PCR products were analyzed by electrophoresis in a $1.5 \%(\mathrm{w} / \mathrm{v})$ agarose gel and stained by ethidium bromide which was visualized under UV illumination.

Real-time PCR analysis was performed on 7900HT Fast Real-Time PCR system using Fast SYBR Green Master Mix (Applied Biosystems, Foster City, USA), and were performed in triplicate on 6 biological replicates. Relative expression levels of Pdgfra in urorectal tissues were determined using beta-actin as internal reference and $2^{-\Delta \Delta \mathrm{Ct}}$ method. The relative expression of Pdgfra between controls and mutants were calculated taking the relative expression level of Pdgfra in controls arbitrarily as one, and expressed as mean \pm S.E.M.

\section{Scanning electron microscopy}

Urorectal regions of E14.5 and E18.5 Pdgfra-cKO and control littermates were dissected and fixed in $2.5 \%$ glutaraldehyde (Merck) in $0.1 \mathrm{M}$ cacodylate buffer (Merck) for
$24 \mathrm{~h}$ at $4{ }^{\circ} \mathrm{C}$, washed in $0.1 \mathrm{M}$ cacodylate buffer $\mathrm{pH} 7.4$ before second fixation in $1 \%$ osmium tetroxide (aqueous) (Merck) $\mathrm{pH} 7.4$ for $1 \mathrm{~h}$ at room temperature. After washings in $0.1 \mathrm{M}$ cacodylate buffer $\mathrm{pH} 7.4$, tissues were dehydrated in a series of graded ethanol until 100\% (EM grade). Critical point drying of dehydrated tissues were performed on Bal-tec CPD 030 Critical Point Dryer (BAL-TEC AGBalzers, Liechtenstein), and sputter coating of tissues were performed on Bal-tec SCD 005 Sputter Coater (BAL-TEC AG-Balzers, Liechtenstein) according to manufacturer's protocols. Samples were examined on Hitachi S-4800FEG scanning electron microscope (Tokyo, Japan).

\section{Immuno-histochemistry}

Paraffin sections ( $8 \mu \mathrm{m}$ in thickness) were prepared and mounted onto TESPA-coated glass slides. Sections were dewaxed in xylene, hydrated in a graded series of alcohol and finally in distilled water. Endogenous peroxidase activity was quenched by incubation of section in methanol containing $3 \% \mathrm{H}_{2} \mathrm{O}_{2}$ at room temperature for $30 \mathrm{~min}$. After washing in water, antigen was retrieved by incubating in $10 \mathrm{mM}$ sodium citrate buffer $(\mathrm{pH} 6.0)$ at $95^{\circ} \mathrm{C}$ for $10 \mathrm{~min}$. After blocking in PBS-T (PBS with 0.1\% Triton) supplemented with $1 \%$ Bovine Serum Albumin (USB Corporation, Cleveland, OH USA) for $1 \mathrm{~h}$ at room temperature, sections were incubated with anti-PDGFRA antibody (Abcam ab124392; 1:100 dilution) in PBS-T supplemented with $1 \%$ Bovine Serum Albumin or Ki67 antibody (BD Pharmigen 556003; 1:100 dilution) in Mouse Ig Blocking Reagent (M.O.M. ${ }^{\mathrm{TM}}$ Immunodetection Kits, Vector Laboratories) for overnight at $4{ }^{\circ} \mathrm{C}$. The sections were washed in PBS and secondary body incubation and signal development were performed using EnVision Detection Systems Peroxidase/DAB, Rabbit/Mouse system (Dako) or M.O.M. ${ }^{\mathrm{TM}}$ Immunodetection Kits (Vector Laboratories) according to manufacturer's protocol. After washing in water, sections were counterstained with Haematoxylin, washed in water, incubated in $2 \%(\mathrm{~W} / \mathrm{V}) \mathrm{NaHCO}_{3}$ for $30 \mathrm{~s}$ before being washed in water. Sections were dehydrated in a graded series of alcohol, dewaxed in xylene and then mounted in DPX mountant (BDH). Images were taken with Nikon Eclipse E600 microscope mounted with Nikon Digital Camera DXM1200F.

\section{Whole mount beta-galactosidase activity staining}

Embryos were fixed in PFA/PBS for $1 \mathrm{~h}$ at $4{ }^{\circ} \mathrm{C}$. X-gal/ IPTG staining was performed at $37^{\circ} \mathrm{C}$ for $18 \mathrm{~h}$ as describe previously [23]. Stained embryos were fixed in PFA/PBS at $4{ }^{\circ} \mathrm{C}$ for $18 \mathrm{~h}$, dehydrated in graded series of alcohol, cleared in toluene (RCI Labscan Ltd, Bangkok, Thailand) before being embedded in paraffin. $10 \mu \mathrm{m}$ thick sections 
were prepared and mounted onto TESPA-coated microscope glasses. Sections were dewaxed in toluene, hydrated in graded series of alcohol before being completely hydrated in water, counter-stained with Nuclear Fast Red according to manufacturer's protocol (Vector Lab. Inc. Burlingham, CA), and mounted in Faramount Aqueous Mounting Medium (Dako).

\section{In situ hybridization}

For section ISH, embryos were fixed in $4 \%$ paraformaldehyde, embedded in paraffin wax and sectioned in $6 \mu \mathrm{m}$. ISH was performed following standard protocols.

\section{Results}

\section{Ethylenethiourea induced urorectal developmental anomalies and down-regulation of Pdgfra in rat embryos}

Ethylenethiourea (ETU) induces anorectal malformations (ARMs) in rat fetuses, providing an ideal animal model to study the pathogenesis of ARMs [24]. ETU-treated embryos displayed urorectal defects which are typified in human ARMs, including delayed genital tubercle outgrowth; incomplete cloaca septation and untubularized urethra [25]. We performed Affymetrix GeneChip (Rat Expression Set 230) analysis in normal and ETU-treated rat embryos with urorectal anomalies to identify genes/pathways implicated in urorectal development. GeneChip analysis followed by real-time PCR analysis in biological replicates identified Pdgfra down-regulation in ETU-treated embryos (Supplementary Figure 1). Immuno-histochemistry confirmed ETU induced down-regulation of Pdgfra, disrupting the spatialtemporal distribution of Pdgfra at the developing urorectum (Supplementary Figure 1).

\section{Pdgfra was tempo-spatially expressed in the urorectal mesenchyme during genital tubercle outgrowth and cloaca septation}

Immuno-histochemistry for Pdgfra was performed on E10.5-E14.5 mouse embryo sections to investigate the tempo-spatial expression of Pdgfra in the developing urorectum from the stage of genital tubercle outgrowth to the completion of cloaca septation. At E10.5, immunoreactivity for Pdgfra was localized at the mesenchyme surrounding the cloaca of the budding genital tubercle (Fig. 1). At E11.5-E12, Pdgfra expressions were detected at most of the genital tubercle, urorectal septum and the hindgut mesenchyme. At E12.5, the urorectal septum developed further, moved downward to the cloaca membrane. The cloaca membrane was consisted of a signal layer of cell. The Pdgfra expression was detected in the mesenchyme of the entire genital tubercle. At E13.5, septation of cloaca nearly completed with the openings of separated urogenital sinus and hindgut connecting to the outside. Pdgfra was expressed in the urorectal septum mesenchyme, in the mesenchyme surrounding the cloaca membrane and the urogenital sinus (Fig. 1). At E14.5, septation completed with the urethral duct and anal opening formation, Pdgfra was further restricted to the mesenchyme adjacent to the urethra and the ureter, to the urorectal septum and at the urethral plate mesenchyme. Expression of Pdgfra in most of the developing urorectal mesenchyme from E10.5 to E14.5 suggested that Pdgfra may be crucial for the genital tubercle outgrowth and the cloaca septation.

\section{Tamoxifen inducible Cre-mediated deletion of gene in Pdgfra-expressing tissues in mouse urorectum}

Tamoxifen (Tm) administration at E9.5 induced X-gal expression to the mesenchyme of the budding genital tubercle of male and female $P d g f r a^{C r e / E R T} ; R 26 R$ embryos as early as $24 \mathrm{~h}$ after Tm administration (filled arrowheads; Supplementary Figure 2A). However, a single dose of Tm at E9.5 was insufficient to induce X-gal expression to all the $P d g f r a$-expressing urorectal mesenchyme cells at the later embryonic stages in Pdgfra ${ }^{C r e / E R T} ; R 26 R$ embryos (compared Fig. 1 and Supplementary Figure 2).

To improve the efficacy of Cre-mediated recombination in the Pdgfra-expressing urorectal mesenchyme, we gave Tm to pregnant females for two consecutive days at E9.5 and E10.5, harvested embryos at E11.5 and E14.5 for examination (Fig. 2). Strong X-gal staining was observed in the peri-cloaca mesenchyme of E11.5 Pdgfra ${ }^{\text {Cre/ERT }}$; R26R embryos (Fig. 2b). By E14.5, X-gal staining was detected at most of the urorectal mesenchyme including the apical genital mesenchyme, genital tubercle mesenchyme, urethral plate mesenchyme, urogenital fold mesenchyme, and the mesenchyme surrounding the urethra (Figs. 2d, e). No X-gal staining was detected in $R 26 R$ embryos (Figs. 2a, c). Therefore, two consecutive Tm administrations at E9.5 and E10.5 was sufficient to induce Cre-mediated recombination to most of the Pdgfra-expressing urorectal mesenchyme cells at the later embryonic stages.

\section{Conditional knockout of Pdgfra in Pdgfra-expressing urorectal tissues in embryos resulted in cloaca septation defects}

To investigate the impact of the conditional knockout of Pdgfra in Pdgfra-expressing urorectal tissues on the urorectal development, we gave Tm to pregnant females at E9.5 for two consecutive days at E9.5 and E10.5, harvested 

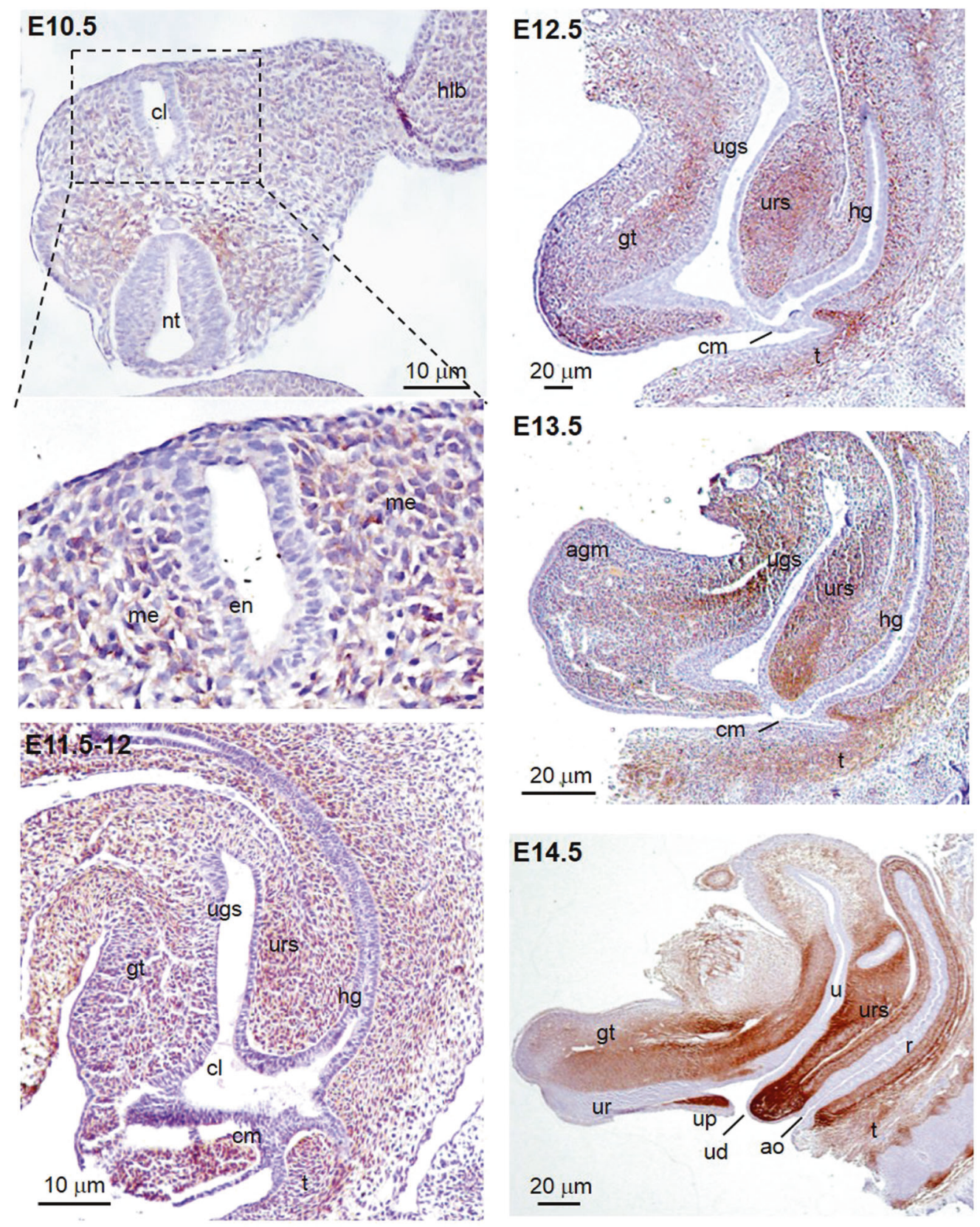

Fig. 1 Pdgfra was expressed in the peri-cloaca and genital tubercle mesenchyme of mouse embryos from E10.5 to E14.5. Immunohistochemistry for Pdgfra was performed on transverse section of E10.5 and mid-sagittal sections of E11.5-E14.5 mouse embryos. Immuno-reactivity for Pdgfra (brown) was localized at the mesenchyme surrounding the cloaca of the budding genital tubercle at E10.5. From E11.5 to E13.5, Pdgfra expression was detected at the genital

embryos at E14.5 and E18.5 for examination (Fig. 3). Male and female E14.5 and E18.5 Pdgfra conditional (Pdgfra$c K O$ ) embryos of the $\mathrm{Tm}$ treatment group were recovered in compliance with the expected Mendelian inheritance. Significant reduction of the expression of Pdgfra mRNA and Pdgfra protein in E14.5 Pdgfra-cKO urorectal tissues were shown by RT-PCR analysis, qPCR analysis and Western

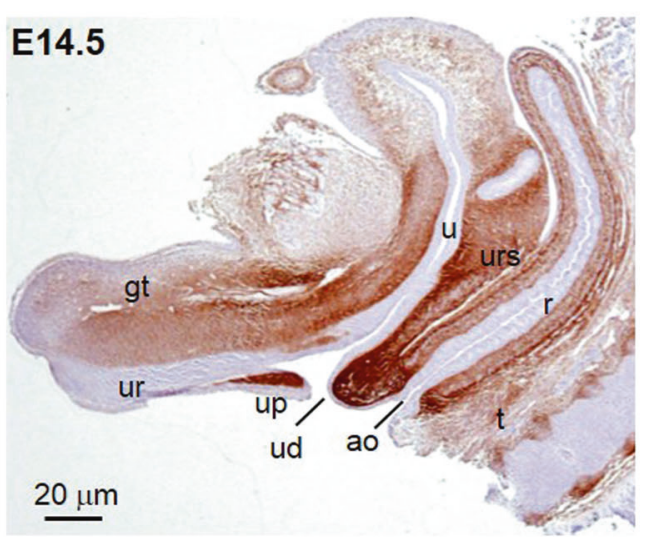

tubercle, urorectal septum and the hindgut mesenchyme. At E14.5, a more restricted expression of Pdgfra was localized at the mesenchyme adjacent to the urethra and the ureter, at the urorectal septum and at the urethral plate mesenchyme. $\mathrm{cl}$ cloaca, $h l b$ hindlimb bud, $n t$ neural tube $g t$ genital tubercle, ugs urogenital sinus, urs urorectal septum, $h g$ hindgut, $\mathrm{cm}$ cloaca membrane, $t$ tail, $u r$ urethra, up urethral plate, $u d$ urethral duct, $a o$ anal opening, $u$ ureter, $r$ rectum

blot analysis (Figs. 4a-c). Absence of Pdgfra expression in the urorectal mesenchyme of E12.5 Pdgfra-cKO was confirmed by immuno-histochemistry (Fig. 4d).

At E14.5, the sizes of the genital tubercle of male and female Pdgfra-cKO embryos were comparable with that of control embryos as revealed by scanning electronic microscopy (SEM) study (Fig. 5). In the genital tubercle of both 
$R 26 R$

A

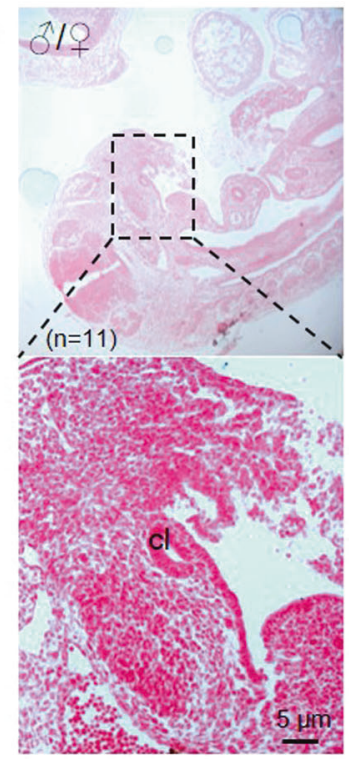

$R 26 R$
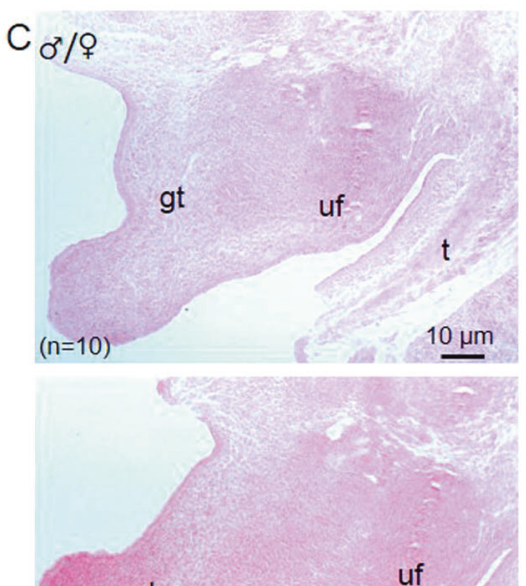

gt
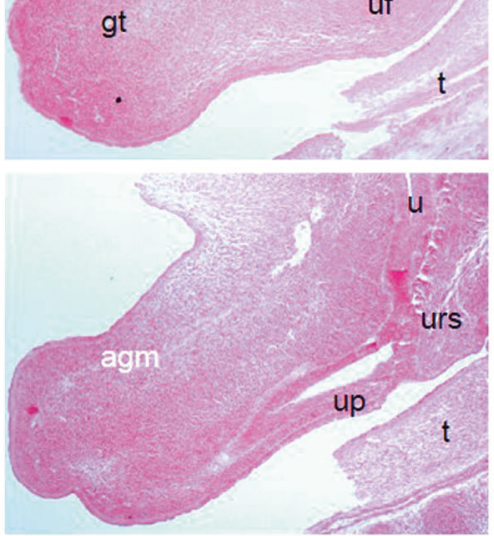

B

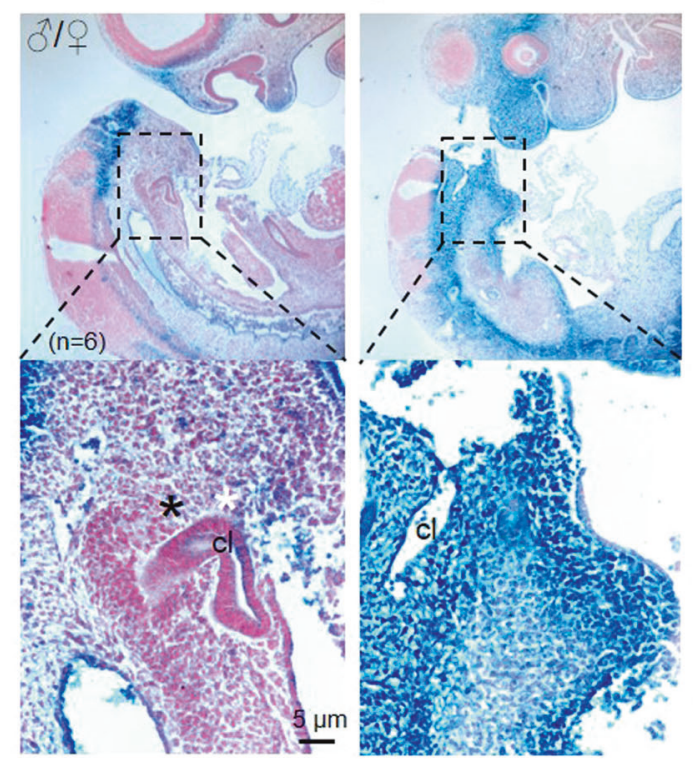

R26R; PdgfraCre/ERT

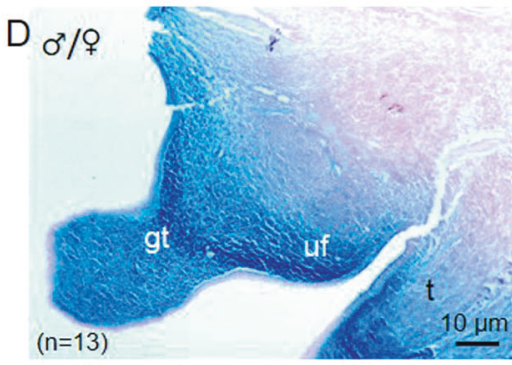

$\mathrm{E}^{\mathrm{x} / \mathrm{T}}$
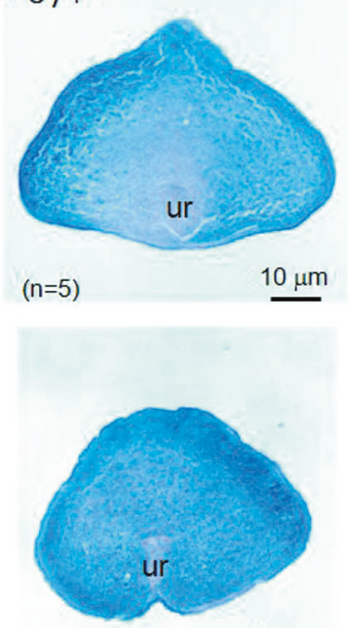

$\underline{10 \mu \mathrm{m}}$
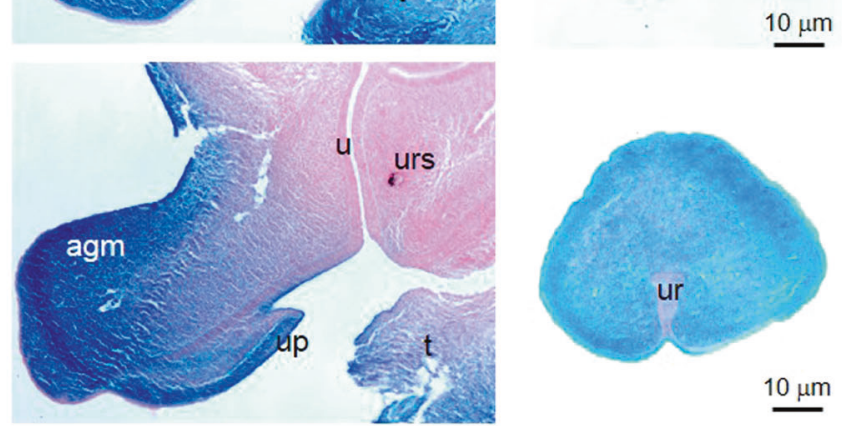

Fig. 2 Pdgfra ${ }^{C r e / E R T}$ drives tamoxifen induced Cre recombination to the peri-cloaca and genital tubercle mesenchyme in mice. Tamoxifen was given to pregnant mice at E9.5 and E10.5, embryos were collected at E11.5 (a, b) or at E14.5 (c, d) for X-gal staining and sectioning. Strong X-gal staining was only observed in R26R; Pdgfra Cre/ERT embryos but not in $R 26 R$ embryos. Region highlighted was shown underneath. $c l$ cloaca, gt genital tubercle, $u$ ureter, urs urorectal septum, up urethral plate, uf urogenital fold, agm apical genital mesenchyme, $t$ tail. $n=$ number of embryos analyzed 
A

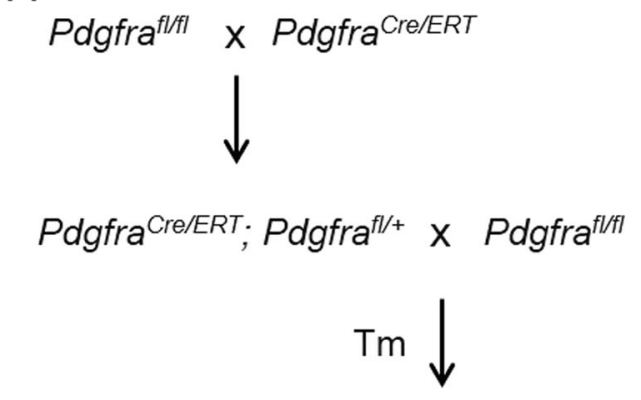

Pdgfra-cKO PdgfraCre/ERT; Pdgfra ${ }^{\text {fft }}$

Control

Pdgfra $^{\text {flft }}$
B

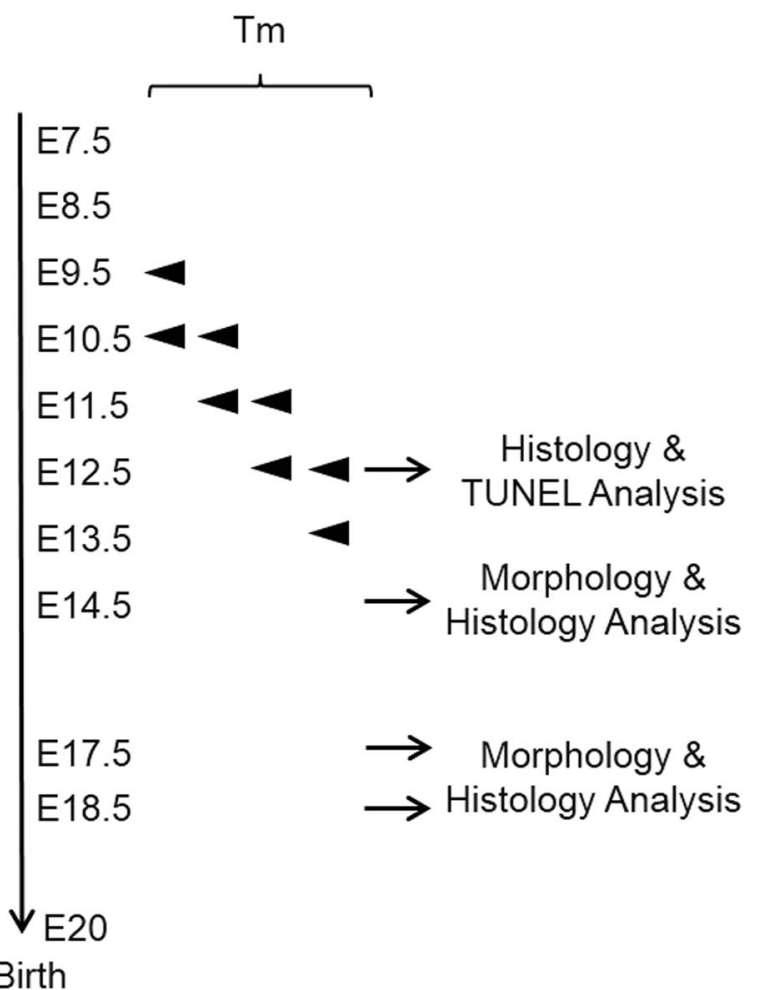

${ }^{E R T} ;$ Pdgfra $\left.{ }^{f l f l}\right)$ and control $\left(C t r l, P d g f r a^{f l / f t}\right)$ embryos. b Tamoxifen (Tm) was given to pregnant females at various embryo days by intragastric gavage, and embryos were collected for analysis

At E18.5, the sizes of the genital tubercle of male and female Pdgfra-cKO embryos were comparable to that of control embryos (Fig. 5). From ventral view, there was an abnormal distal to proximal urethral opening along the ventral side of the genital tubercle in male and female $P d g f r a-c K O$ embryos, in that prepuce and urethra were not developed normally and were not fused ventrally in $P d g f r a-$ cKO embryos. Mid-sagittal sections of Pdgfra-cKO and control embryos revealed that the distance from the anal opening to the tail base was lengthened in Pdgfra-cKO embryos of both genders, which indicated that anal openings were anteriorly displaced in Pdgfra-cKO embryos.

We also gave tamoxifen to pregnant mice from the crossing at E10.5/11.5; E11.5/12/5 and E12.5/13.5, collected embryos at E14.5 and/or E17.5 for histology and morphology analysis. Urorectal defects could only be detected in the Pdgfra-cKO embryos of the E10.5/11.5 Tm group, but in general, with lower incidence and milder severity of the abnormalities. Only one E14.5 mutant Pdgfra-cKO embryo of E10.5/11/5 Tm group showed severe genital tubercle detects as that of 9.5/10.5 Tm group, but all the other Pdgfra-cKO embryos only displayed milder genital tubercle defects which included slightly enlarged urethral opening at E14.5 and incomplete ventral midline 


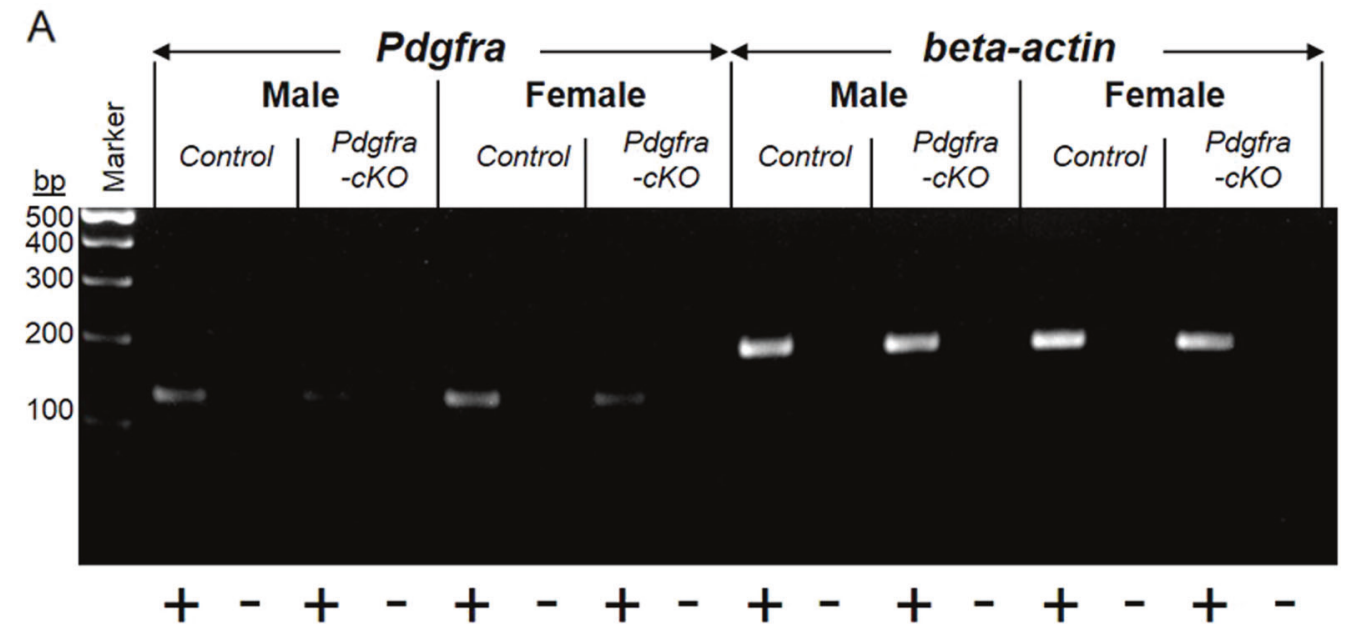

B

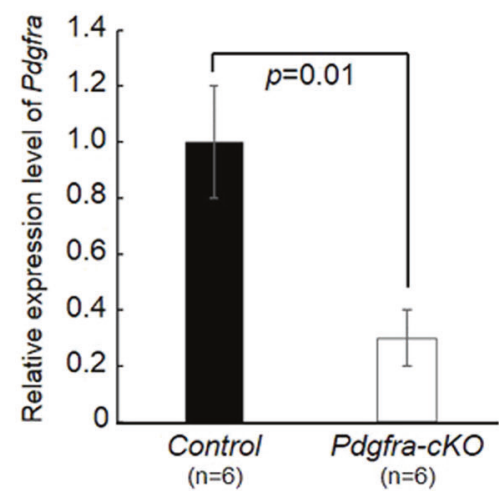

C

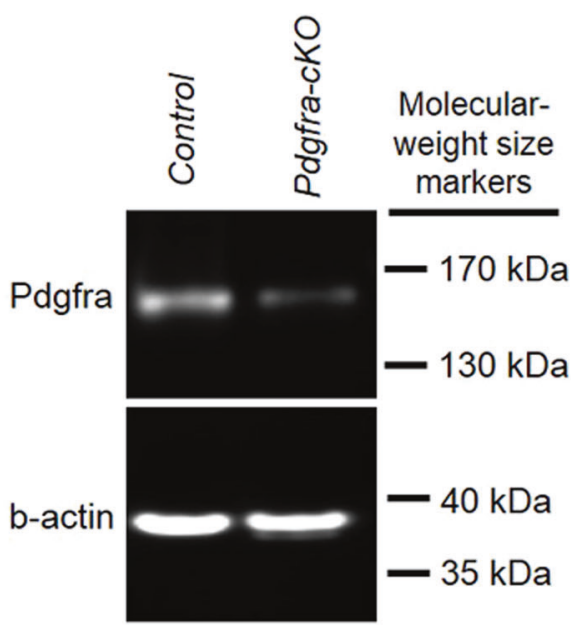

Fig. 4 Conditional deletion of Pdgfra in mouse embryos. Tamoxifen was given to pregnant mice at E9.5 and E10.5, E14.5 embryos were collected to isolate total RNAs of the urorectum for RT-PCR analysis (a) and qPCR analysis (b). Expression of beta-actin RNA was used as internal control. "+" means with RT; "-" means without RT (negative control). Relative expression levels of Pdgfra (mean \pm S.E.M.) in control and mutant urorectum were shown and the relative expression level of Pdgfra in controls were taken arbitrarily as one. Western blot
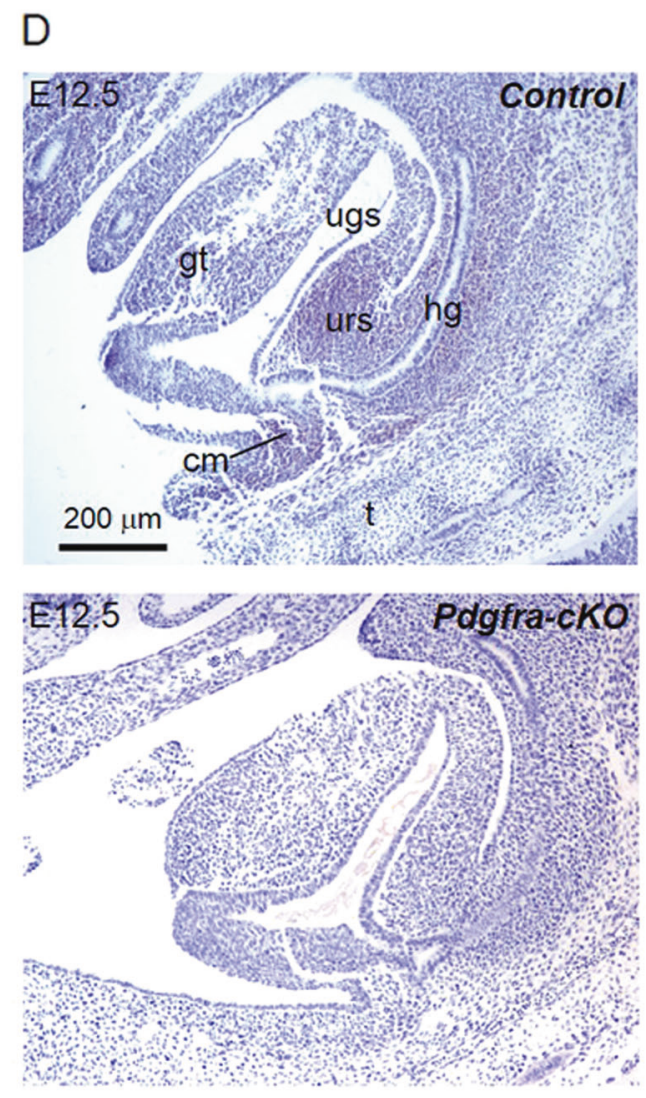

analysis was performed on E14.5 urorectum to detect the expression of Pdgfra and beta-actin (b-actin) was used as loading controls (c). E12.5 embryos were collected for immuno-histochemistry (d). Pdgfra expression (brown) was detected in the urorectal mesenchyme of E12.5 control embryos. In contrast, no Pdgfra expression was detected in the urorectal mesenchyme of E12.5 Pdgfra-cKO. gt genital tubercle, ugs urogenital sinus, urs urorectal septum, $h g$ hindgut, $\mathrm{cm}$ cloaca membrane. $n=$ number of embryos analyzed 

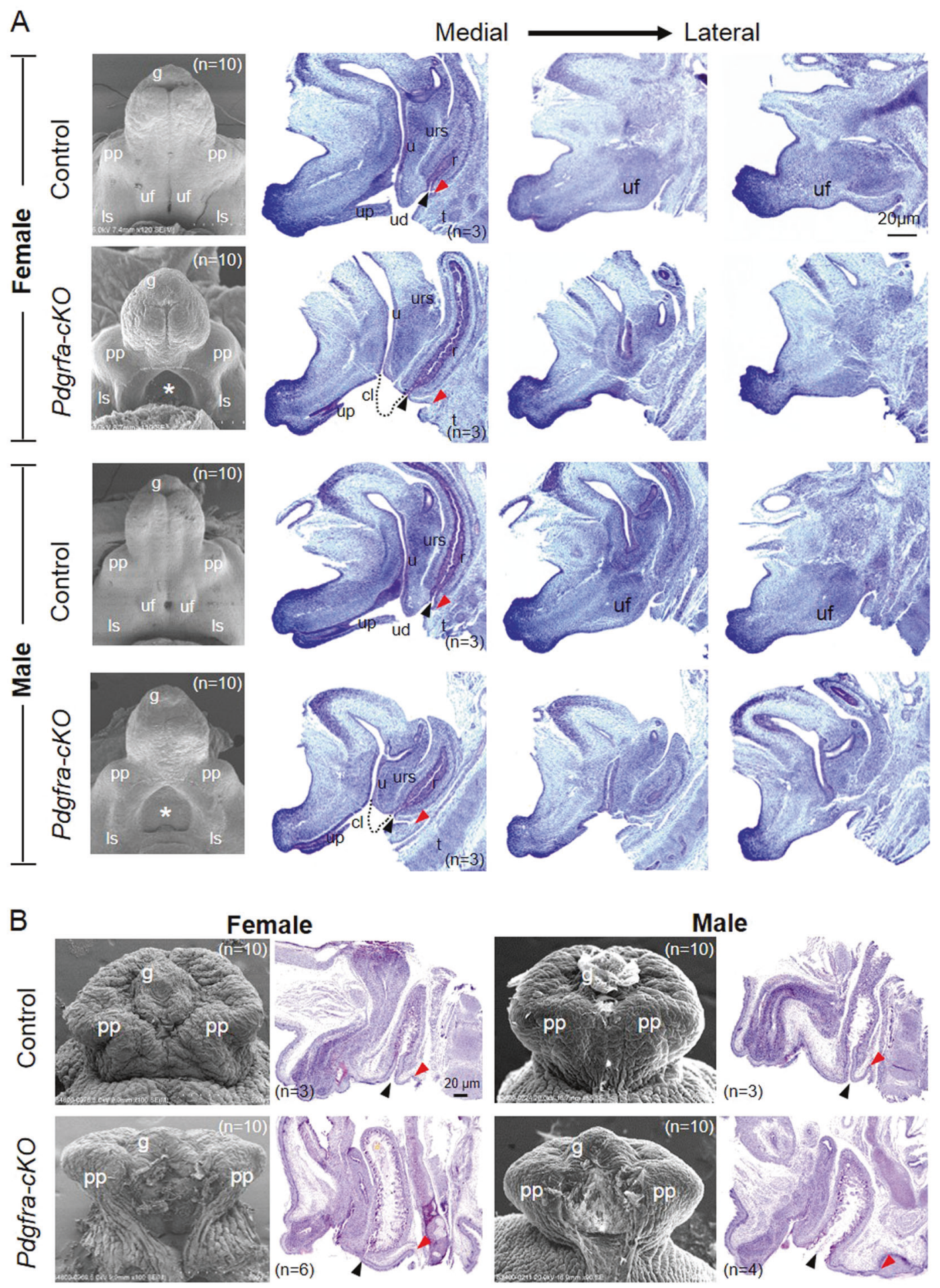

Fig. 5 Conditional deletion of Pdgfra in the mesenchyme of the developing external genitalia causes defective external genitalia development. Tamoxifen was given to pregnant mice at E9.5 and E10.5, embryos were collected at E14.5 (a) and E18.5 (b) for scanning electron microscopy and histology analysis. Medial to lateral sagittal sections of E14.5 control and Pdgfra conditional knockout (Pdgfra$c K O s$ ) embryos revealed that the urorectal septum (urs) and the urogenital fold (uf) were not developed normally in female and male Pdgfra-cKOs. The urs was shorter and not reaching the level of the

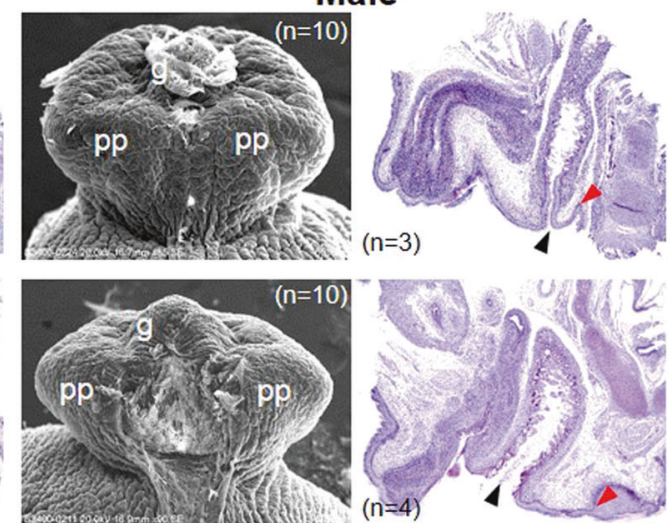

cloaca membrane in Pdgfra-cKOs (dotted lines indicated the expected normal locations of the urs). Prepuce and urethra were not developed normally in E18.5 male and female Pdgfra-cKOs. Anal openings were anteriorly displaced in male and female Pdgfra-cKOs. Red arrowhead indicates the location of the tail base. Black arrowhead indicates the anal opening. $p p$ prepuce, $u f$ urogenital fold, $l s$ labioscrotal fold, urs urorectal septum, $r$ rectum, $u$ urethra, $c l$ cloaca, $u p$ urethral plate, $u d$ urethral duct, $t$ tail, $g$ glans. $n=$ number of embryos analyzed 

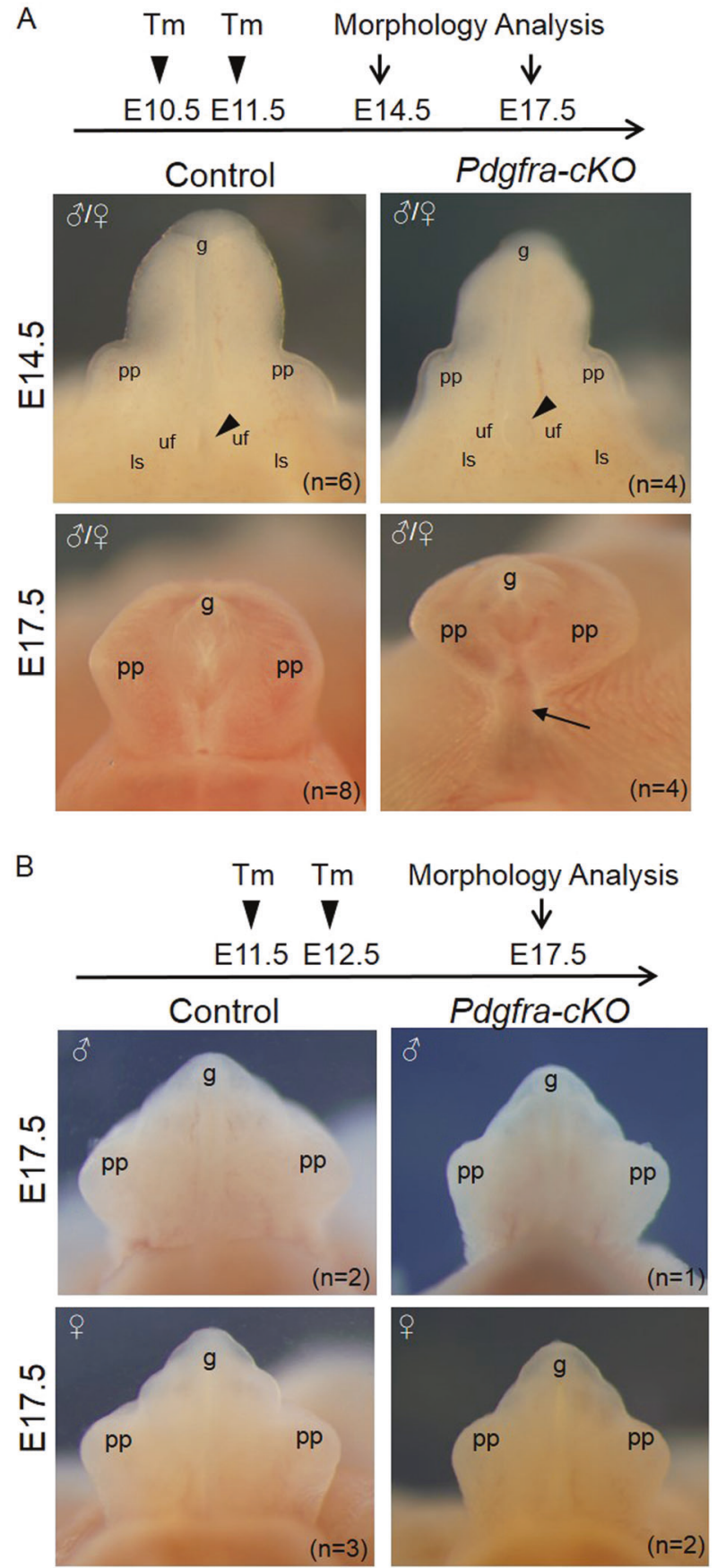

Fig. 6 Conditional deletion of Pdgfra in the mesenchyme of the developing external genitalia at later embryonic stages resulted in milder defective external genitalia development. Tamoxifen was given to pregnant mice at E10.5 and E11.5 (a) or E11.5 and E12.5 (b), embryos were collected at E14.5 and/or E17.5 for morphology analysis. Black arrowhead indicates the location of the urethral opening. Black arrow indicates the proximal untubularized urethra. $p p$ prepuce, $u f$ urogenital fold, $l s$ labioscrotal fold, $g$ glans. $n=$ number of embryos analyzed

fusion of prepuce and proximal untubularized urethra (Fig. 6a). No genital tubercle defects could be detected in all the Pdgfra-cKO embryo of E11.5/12.5 and E12.5/13.5 Tm groups (Fig. $6 \mathrm{~b}$ and data not shown).

Urorectal anomalies of Pdgfra-cKO embryos of different $\mathrm{Tm}$ groups were summarized as shown in Table 1.

\section{Deletion of Pdgfra induced apoptosis of the urorectal mesenchyme}

To test if deletion of Pdgfra induced apoptosis of the

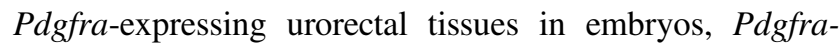
$c K O$ and control E12.5 embryos were examined by TUNEL assay. Apoptotic cells were abundantly localized at the mesenchyme surrounding the cloaca and the urethra; at the urorectal septum, apical genital mesenchyme and the urethral plate of male and female Pdgfra-cKO embryos (Figs. 7a, b). In contrast, apoptotic cells were only localized at the tip of the urethra and at the proximal cloaca membrane in normal E12.5 embryos. Percentages of the apoptotic cells in the peri-urethra and the peri-cloaca mesenchyme were significantly elevated in Pdgfra-cKO embryos as compared to that of control littermates (Fig. 7c).

Pdgfra regulates survival and proliferation in skeletal development via suppression of p53 [15]. Deletion of Pdgfra induced a marked production of $\mathrm{p} 53$ protein and the phosphorylation of p53 at the serine 46 position in mutants (Fig. 8). In line with the p53 induction of the transcription of its target gene $\mathrm{Ndrgl}$ ( $\mathrm{N}$-myc downregulated gene 1) and Ndrg1 is necessary for p53-dependent apoptosis [26], Ndrg1 protein level was markedly increased in mutant urorectum. Elevated Nrdg1 induced a cleavage of inactive Caspase-3 to active form of Caspase 3 (C-Caspase-3), causing cell apoptosis of the urorectal mesenchyme of male and female Pdgfra-cKO embryos.

Immuno-histochemistry for $\mathrm{Ki}-67$ (proliferative cell marker) on sections of Pdgfra-cKO and control E12.5 embryos indicated that the proliferation of the urorectal mesenchyme of male and female Pdgfra-cKO embryos were largely unaffected by the deletion of Pdgfra (Supplementary Figure 3).

\section{Discussion}

This study shows for the first time that Pdgfra is required for the cloaca septation and urethra tubularization of the urorectal development, and deletion of Pdgfra in embryos causes cloaca septation defect, leading to abnormal urethra tubularization in mice. Furthermore, our data also shows that Pdgfra is required for the survival of urorectal mesenchyme in normal development, deletion of Pdgfra causes death of the urorectal mesenchyme and defective cloaca septation. 
Table 1 Genital tubercle (GT) defects of Pdgfra-cKO embryos of different Tm groups

\begin{tabular}{lllll}
\hline Tm & Collection & Embryos $(n)$ & Pdgfra-cKO $(n)$ & GT defects $(n)$ \\
\hline E9.5/10.5 & E14.5 & $146(\mathrm{M}: 64 ; \mathrm{F}: 82)$ & $37(25 \%)(\mathrm{M}: 17 ; \mathrm{F}: 20)$ & $+(37)$ \\
& E18.5 & $143(\mathrm{M}: 78 ; \mathrm{F}: 65)$ & $39(27 \%)(\mathrm{M}: 12 ; \mathrm{F}: 27)$ & $+(39)$ \\
E10.5/11.5 & E14.5 & $18(\mathrm{M}: 8 ; \mathrm{F}: 10)$ & $5(27 \%)(\mathrm{M}: 2 ; \mathrm{F}: 3)$ & $+(1) ; \pm(4)$ \\
& E17.5 & $24(\mathrm{M}: 13 ; \mathrm{F}: 11)$ & $7(29 \%)(\mathrm{M}: 3 ; \mathrm{F}: 4)$ & $\pm(7)$ \\
E11.5/12/5 & E17.5 & $8(\mathrm{M}: 3 ; \mathrm{F}: 5)$ & $3(37 \%)(\mathrm{M}: 1 ; \mathrm{F}: 2)$ & $-(4)$ \\
E12.5/13.5 & E17.5 & $8(\mathrm{M}: 4 ; \mathrm{F}: 4)$ & $3(37 \%)(\mathrm{M}: 1 ; \mathrm{F}: 2)$ & $-(4)$ \\
\hline
\end{tabular}

Time of collection, number of total embryos and mutant embryos, genders, \% of Pdgfra-cKO embryos, GT defects and number of mutants (in parenthesis) showing different GT defects of different Tm treatment groups were indicated. "+": severe GT defects include the urorectal septum retardation, urogenital fold dysplasia, no ventral midline fusion of prepuce and untubularized urethra. " \pm ": mild GT defect includes slightly enlarged urethral opening, incomplete ventral midline fusion of prepuce, and proximal untubularized urethra. "-": no GT defect

Tm tamoxifen, $M$ male, $F$ female
The correct time and level of Pdgfra expression during embryonic development are critical for the proper development of the urorectal mesenchyme and its derivatives. The Pdgfra-expressing mesenchyme at E10.5 (genital tubercle outgrowth phase) derived into the peri-cloacal mesenchyme, the urs mesenchyme, the apical genital mesenchyme and the lateral mesenchyme of the urethra at E14.5. When Pdgfra was deleted at around E10.5 (E9.5 + E10.5 Tm group), excessive apoptosis was detected at the mesenchyme of all these regions of E12.5 Pdgfra-cKO mouse embryos, which resulted in urorectal defects at E14.5. Urorectal defects with lower incidence and milder severity could only be detected in the Pdgfra-cKO embryos when Pdgfra was deleted at around E11.5 (E10.5 + E11.5 Tm group). Furthermore, Pdgfra-cKO embryos did not develop any urorectal anomaly if Pdgfra was deleted at around E12.5 (E11.5 + E12.5 Tm group) and at E13.5 (E12.5 + E13.5 Tm group). Taken all these indicated that tempo-spatial expression of Pdgfra in the developing urorectal mesenchyme between E10.5 and E11.5 was critical for cloaca septation and subsequent urorectal development in mice.

The excessive cell death of the urorectum disturbed the ventral elongation of the urs and the cloaca septation, as well as urs proximal-distal movement along the ventral edge of the genital tubercle. In addition, the excessive cell death of the apical genital mesenchyme and the peri-urethra mesenchyme also caused defective growth and folding of the genital tubercle mesenchyme. As the consequences of the apoptosis and the defective growth of the urs, the apical genital and the peri-urethra mesenchyme, the urethral folds fail to form and fuse along the ventral midline of the genital tubercle, leading to incomplete urethra tubularization and a big "hole" at the genital tubercle root at E14.5 and at the perineum at E18.5.

We also discovered that deletion of Pdgfra induced a production of $\mathrm{p} 53$, an apoptotic factor, and phosphorylation of p53 at the position of Serine 46 (p-p56(Ser46)) in uroerctum. It has been shown that p53 induced the transcription of $\mathrm{Ndrgl}$ (N-myc downregulated gene 1) and Ndrg1 was necessary for p53-dependent apoptosis via activation of Caspase 3 [26]. In line with p53 induction of Ndrg1, we observed elevated Ndrg1 protein level and production of active Caspase 3 (C-Caspase-3) and cell death in $P d g f r a-c K O$ urorectum.

We have crossed $P d g f r a^{f / /+} ; P d g f r a{ }^{C r / E R T}$ mice with $P d g f r a^{f l f l}$ mice and administered Tm at E7.5 and E8.5, only few Pdgfra-cKO embryos could be collected at E14.5 and no Pdgfra-cKO embryos could survive up to E17.5. It demonstrated that conditional deletion of Pdgfra at early embryonic stage prior to E9.5 resulted in early embryonic lethality, which was consistent with the phenomenon reported in Pdgfra-/- mutant embryos [13].

In mice, genital tubercle outgrowth starts at around E10. In both the E12.5 and the E14.5 Pdgfra-cKO mutants of the E7.5 Tm and E8.5 Tm groups, genital tubercle outgrowth appeared largely unaffected but the mutant genital tubercles were smaller (data not shown). In addition, genital tubercle outgrowth of mutant embryos of E9.5 Tm and E9.5 + E10.5 Tm groups also proceeded normally, but the mutant genital tubercles were smaller. Taken all these together may suggest that deletion of Pdgfra prior to genital tubercle outgrowth was insufficient to cause genital tubercle outgrowth defect. However, one has to be cautious in interpreting the data because the efficiency of the Cre-mediated deletion of Pdgfra has to be determined to examine if the lack of genital tubercle outgrowth defect is the consequence of insufficient deletion of Pdgfra in these mutants. Pdgfra displays sexual dimorphic expression pattern in gonad, regulates testis organization and Leydig cell differentiation of early testis development [27]. However, it is not known if early testis developmental defect in Pdgfra-/- mice affects the subsequent urethra tubularization of male external genitalia.

Pathways and transcription factors such as SHH, BMP, FGF, WNT, Eph/ephrin, and HOX family have been implicated in the urorectal development. These signaling 
Fig. 7 Elevated cell death of the urorectal mesenchyme of Pdgfra-conditional knockout embryos. Transverse (a) and mid-sagittal (b) sections of E12.5 mutant and control embryos were analyzed using TUNEL analysis. c Percentages of apoptotic cells in the periurethra and peri-cloaca mesenchyme of wild-type (filled bar) and Pdgfra-cKO embryos (un-filled bars) were shown. Apoptotic cells (red) were abundantly localized at the mesenchyme surrounding the cloaca and the urethra (a); at the urorectal septum, apical genital mesenchyme and the urethral plate of the mutant embryos. In contrast, apoptotic cells were localized only at the tip of the urethra (future urethra orifice) and at the cloaca membrane.

Regions highlighted with dotted line were magnified and shown on the right. $u r$ urethra, $c l$ cloaca, agm apical genital mesenchyme, up urethral plate, ut urethral tip, $\mathrm{cm}$ cloaca membrane urs urorectal septum. $n=$ number of embryos analyzed
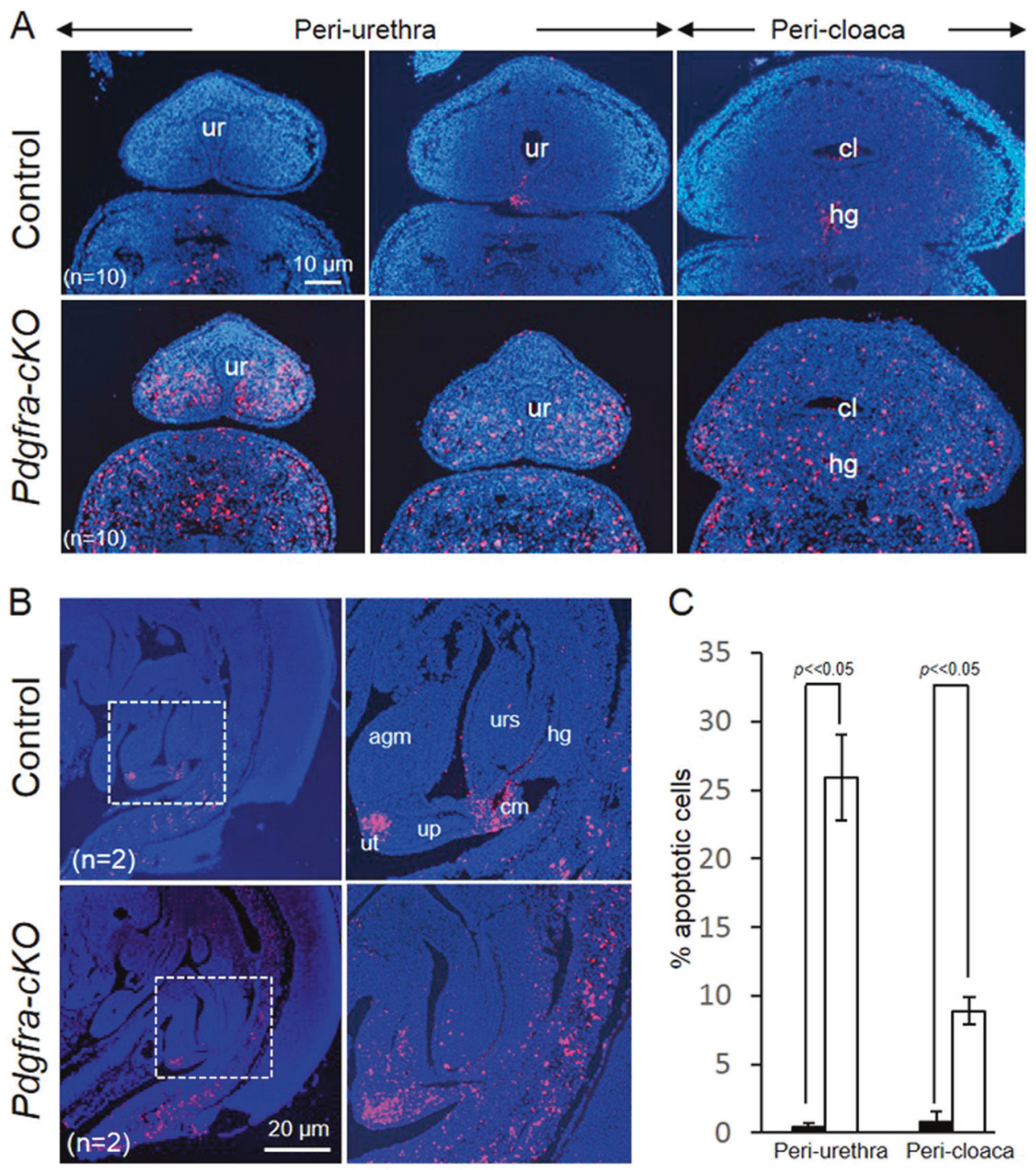

pathways or factors coordinated with each other to regulate the urorectal development and participate in the regulation of cell apoptosis [25]. Bmp4 expression at the apical genital mesenchyme and at the urethral plate mesenchyme was slightly down-regulated in the Pdgfra-cKO mutant genital tubercles of E9.5 + E10.5 Tm group (Supplementary Figure 4). Bmp4 have been demonstrated to mediate cell apoptosis in several tissues [28, 29, 30, 31]. Pdgfra has also been suggested to be a target of Gli factors, linking $\mathrm{Hh}$ and PDGF signaling [32]. The interactions between PDGFRA signaling and other signaling pathways in the regulation of urorectal development worth further investigation in future.

In summary, Pdgfra is required for the process of cloaca septation. Elevated apoptosis was detected in the pericloacal, the peri-urethra mesenchyme and the urs mesenchyme of Pdgfra-cKO mutants, associated with an induction of p53 and activation of caspase- 3 in Pdgfra-cKO embryos. Dysregulated Pdgfra signaling induced urorectal defects resembling human congenital diseases include the anorectal malformations and hypospadias. Therefore, perturbation of PDGFRA signaling may contribute to anorectal malformations and hypospadias in human.

In conclusion, we demonstrated a temporal and spatial requirement for Pdgfra mediated signaling in the urorectal development, and its dysregulation could cause urethra tubularization defects and hypospadias-like phenotypes in mice.

Acknowledgements Authors thanks the technical staff of the Electron Microscope Unit, The University of Hong Kong for their expert assistance in the scanning electron microscopy study. This work is supported by the Health and Medical Research Fund, HKSAR (Project No.: 02132306) and Seed Fund for Basic Research, HKU (Project No.: 201411159117) to VCHL.

\section{Compliance with ethical standards}

Conflict of interest The authors declare that they have no conflict of interest. 


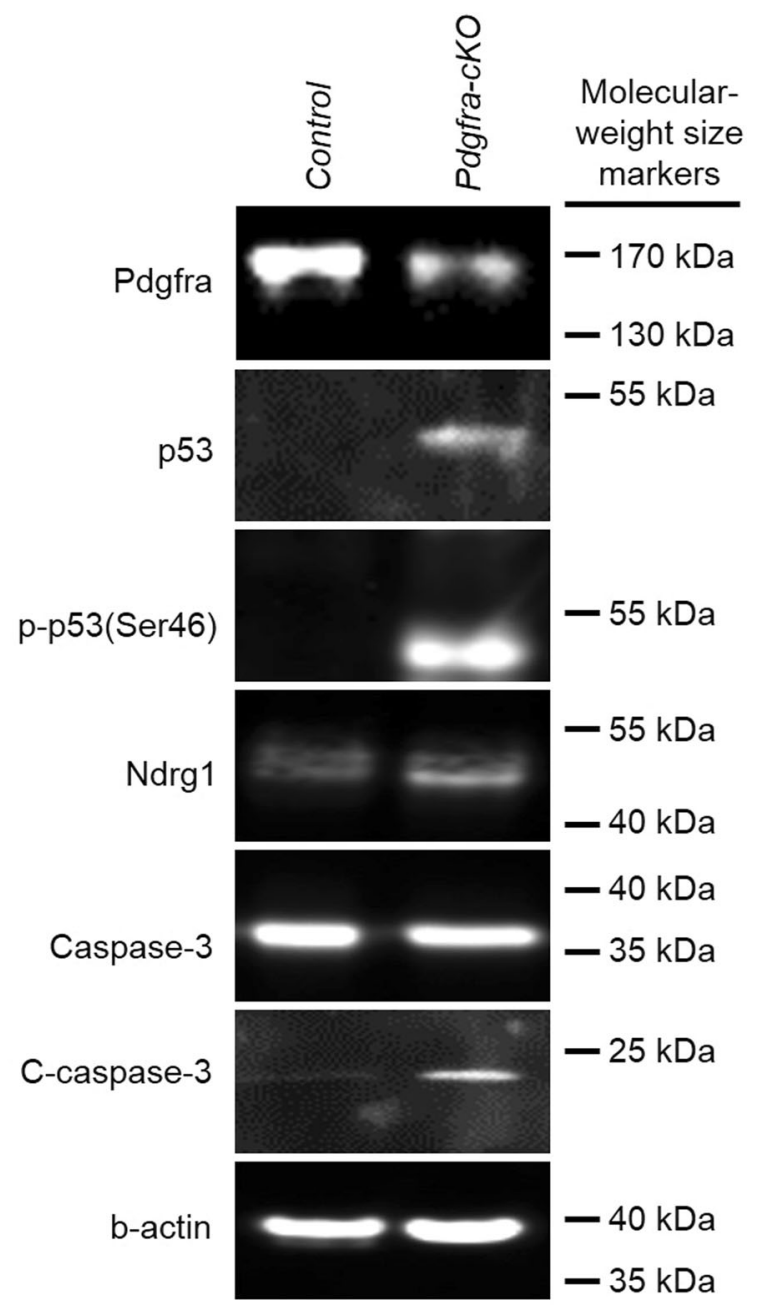

Fig. 8 Deletion of Pdgfra induced phosphorylation of p53 and activation of Caspase 3 in the genital tubercle. Tamoxifen was given to pregnant mice at E9.5 and E10.5, embryos were collected at E12.5 to isolate protein of the urorectum. Proteins of 6 Pdgfra-cKO and control urorectum were pooled and separated by polyacrylamide gel electrophoresis. Expressions of Pdgfra, Caspase 3, activated Caspase 3 (C-Caspase 3), p53, phosphorylated p53 (p-p53(Ser46)), Ndrg1 and beta-actin (b-actin) were analyzed by western blotting

\section{References}

1. Perriton CL, Powles N, Chiang C, Maconochie MK, Cohn MJ. Sonic hedgehog signaling from the urethral epithelium controls external genital development. Dev Biol. 2002;247:26-46.

2. Cohn MJ. Development of the external genitalia: conserved and divergent mechanisms of appendage patterning. Dev Dyn. 2011;240:1108-15

3. Springer A, van den Heijkant M, Baumann S. Worldwide prevalence of hypospadias. J Pediatr Urol. 2016;12:152 e151-157.

4. Kohler N, Lipton A. Platelets as a source of fibroblast growthpromoting activity. Exp Cell Res. 1974;87:297-301.

5. Ross R, Glomset J, Kariya B, Harker L. A platelet-dependent serum factor that stimulates the proliferation of arterial smooth muscle cells in vitro. Proc Natl Acad Sci USA. 1974;71: 1207-10.

6. Westermark B, Wasteson A. A platelet factor stimulating human normal glial cells. Exp Cell Res. 1976;98:170-4.
7. Bergsten E, Uutela M, Li X, Pietras K, Ostman A, Heldin CH, et al. PDGF-D is a specific, protease-activated ligand for the PDGF beta-receptor. Nat Cell Biol. 2001;3:512-6.

8. LaRochelle WJ, Jeffers M, McDonald WF, Chillakuru RA, Giese NA, Lokker NA, et al. PDGF-D, a new protease-activated growth factor. Nat Cell Biol. 2001;3:517-21.

9. Li X, Ponten A, Aase K, Karlsson L, Abramsson A, Uutela M, et al. PDGF-C is a new protease-activated ligand for the PDGF alpha-receptor. Nat Cell Biol. 2000;2:302-9.

10. Heidaran MA, Pierce JH, Yu JC, Lombardi D, Artrip JE, Fleming $\mathrm{TP}$, et al. Role of alpha beta receptor heterodimer formation in beta platelet-derived growth factor (PDGF) receptor activation by PDGF-AB. J Biol Chem. 1991;266:20232-7.

11. Matsui T, Heidaran M, Miki T, Popescu N, La Rochelle W, Kraus $\mathrm{M}$, et al. Isolation of a novel receptor cDNA establishes the existence of two PDGF receptor genes. Science. 1989;243:800-4.

12. Hoch RV, Soriano P. Roles of PDGF in animal development. Development. 2003;130:4769-84.

13. Soriano P. The PDGF alpha receptor is required for neural crest cell development and for normal patterning of the somites. Development. 1997;124:2691-2700.

14. Heldin CH, Westermark B. Mechanism of action and in vivo role of platelet-derived growth factor. Physiol Rev. 1999;79:1283-316.

15. Fantauzzo KA, Soriano P. PI3K-mediated PDGFRalpha signaling regulates survival and proliferation in skeletal development through p53-dependent intracellular pathways. Genes Dev. 2014;28:1005-17.

16. Orr-Urtreger A, Bedford MT, Do MS, Eisenbach L, Lonai P. Developmental expression of the alpha receptor for plateletderived growth factor, which is deleted in the embryonic lethal Patch mutation. Development. 1992;115:289-303.

17. Orr-Urtreger A, Lonai P. Platelet-derived growth factor-A and its receptor are expressed in separate, but adjacent cell layers of the mouse embryo. Development. 1992;115:1045-58.

18. Schatteman GC, Morrison-Graham K, van Koppen A, Weston JA, Bowen-Pope DF. Regulation and role of PDGF receptor alphasubunit expression during embryogenesis. Development. 1992;115:123-31.

19. Tallquist MD, Soriano P. Cell autonomous requirement for PDGFRalpha in populations of cranial and cardiac neural crest cells. Development. 2003;130:507-18.

20. Geller F, Feenstra B, Carstensen L, Pers TH, van Rooij IA, Korberg IB, et al. Genome-wide association analyses identify variants in developmental genes associated with hypospadias. Nat Genet. 2014;46:957-63.

21. Kang SH, Fukaya M, Yang JK, Rothstein JD, Bergles DE. NG2 + CNS glial progenitors remain committed to the oligodendrocyte lineage in postnatal life and following neurodegeneration. Neuron. 2010;68:668-81.

22. Qian C, Wong CWY, Wu Z, He Q, Xia H, Tam PKH, et al. Stage specific requirement of platelet-derived growth factor receptoralpha in embryonic development. PLoS One. 2017;12:e0184473.

23. Sanes JR, Rubenstein JL, Nicolas JF. Use of a recombinant retrovirus to study post-implantation cell lineage in mouse embryos. EMBO J. 1986;5:3133-42.

24. Qi BQ, Beasley SW, Frizelle FA. Clarification of the processes that lead to anorectal malformations in the ETU-induced rat model of imperforate anus. J Pediatr Surg. 2002;37:1305-12.

25. Ng RC, Matsumaru D, Ho AS, Garcia-Barcelo MM, Yuan ZW, Smith D, et al. Dysregulation of Wnt inhibitory factor 1 (Wif1) expression resulted in aberrant Wnt-beta-catenin signaling and cell death of the cloaca endoderm, and anorectal malformations. Cell Death Differ. 2014;21:978-89.

26. Stein S, Thomas EK, Herzog B, Westfall MD, Rocheleau JV, Jackson RS 2nd, et al. NDRG1 is necessary for p53-dependent apoptosis. J Biol Chem. 2004;279:48930-40. 
27. Brennan J, Tilmann C, Capel B. Pdgfr-alpha mediates testis cord organization and fetal Leydig cell development in the XY gonad. Genes Dev. 2003;17:800-10.

28. Gambaro K, Aberdam E, Virolle T, Aberdam D, Rouleau M. BMP-4 induces a Smad-dependent apoptotic cell death of mouse embryonic stem cell-derived neural precursors. Cell Death Differ. 2006;13:1075-87.

29. Graham A, Francis-West P, Brickell P, Lumsden A. The signalling molecule BMP4 mediates apoptosis in the rhombencephalic neural crest. Nature. 1994;372:684-6.
30. Jernvall J, Aberg T, Kettunen P, Keranen S, Thesleff I. The life history of an embryonic signaling center: BMP-4 induces p21 and is associated with apoptosis in the mouse tooth enamel knot. Development. 1998;125:161-9.

31. Trousse F, Esteve P, Bovolenta P. Bmp4 mediates apoptotic cell death in the developing chick eye. J Neurosci. 2001;21:1292-301.

32. Lin C, Chen MH, Yao E, Song H, Gacayan R, Hui CC, et al. Differential regulation of Gli proteins by Sufu in the lung affects PDGF signaling and myofibroblast development. Dev Biol. 2014;392:324-33. 